\title{
Time Resolved Thermodynamics Associated with Diatomic Ligand Dissociation from Globins
}

\author{
Jaroslava Miksovska and Luisana Astudillo \\ Department of Chemistry and Biochemistry, Florida International University Miami FL
}

USA

\section{Introduction}

Ligand-induced conformational transitions play an eminent role in the biological activity of proteins including recognition, signal transduction, and membrane trafficking. Conformational transitions occur over a broad time range starting from picosecond transitions that reflect reorientation of amino acid side chains to slower dynamics on the millisecond time-scale that correspond to larger domain reorganization (Henzler-Wildman et al., 2007). Direct characterization of the dynamics and energetics associated with conformational changes over such a broad time range remains challenging due to limitations in experimental protocols and often due to the absence of a suitable molecular probe through which to detect structural reorganization. Photothermal methods such as photoacoustic calorimetry (PAC) and photothermal beam deflection provide a unique approach to characterize conformational transitions in terms of time resolved volume and enthalpy changes (Gensch\&Viappiani, 2003; Miksovska\&Larsen, 2003). Unlike traditional spectroscopic techniques that are sensitive to structural changes confined to the vicinity of a chromophore, photothermal methods monitor overall changes in volume and enthalpy allowing for the detection of structural transitions that are spectroscopically silent (i.e. do not lead to optical perturbations of either intrinsic or extrinsic chromophores).

Myoglobin $(\mathrm{Mb})$ and hemoglobin $(\mathrm{Hb})$ play a crucial role in the storage and transport of oxygen molecules in vertebrates and have served as model systems for understanding the mechanism through which protein dynamics regulate ligand access to the active site, ligand affinity and specificity, and, in the case of hemoglobin, oxygen binding cooperativity. $\mathrm{Mb}$ and individual $\mathrm{\alpha}$ - and $\beta$ - subunits of $\mathrm{Hb}$ exhibit significant structural similarities, i.e. the presence of a five coordinate heme iron with a His residue coordinated to the central iron (proximal ligand) and a characteristic "3-on-3" globin fold (Fig. 1)(Park et al., 2006; Yang\&Phillips Jr, 1996). Both proteins reversibly bind small gaseous ligands such as $\mathrm{O}_{2}, \mathrm{CO}$, and NO. The photo-cleavable Fe-ligand bond allows for the monitoring of transient deoxy intermediates using time-resolved absorption spectroscopy (Carver et al., 1990; Esquerra et al., 2010; Gibson et al., 1986) and time resolved X-ray crystallography (Milani et al., 2008; Šrajer et al., 2001). Based on spectroscopic data and molecular dynamics approaches (Bossa et al., 2004; Mouawad et al., 2005), a comprehensive molecular mechanism for ligand migration in $\mathrm{Mb}$ was proposed including an initial diffusion of the photo-dissociated $\mathrm{CO}$ molecule into the internal network of hydrophobic cavities, followed by a return 

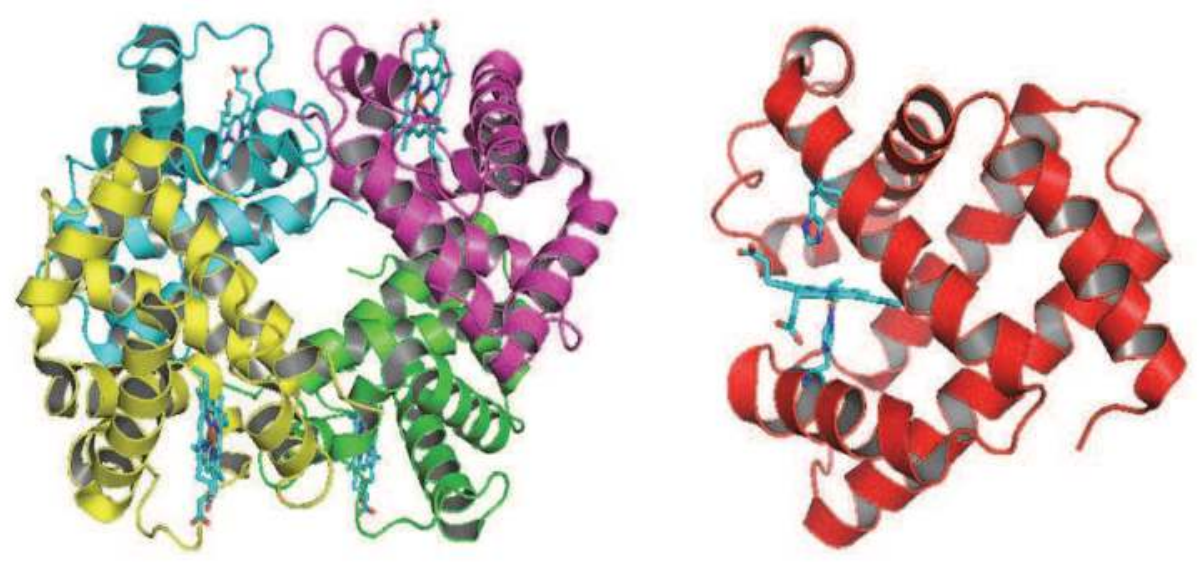

Fig. 1. Left: Ribbon representation of the tetrameric human Hb structure (PBD entry 1FDH). Right: horse heart Mb structure (PDB entry 1WLA). The heme prosthetic groups are shown as sticks. In the case of $\mathrm{Mb}$, the distal and proximal histidine are visualized.

into the distal pocket and subsequent rebinding to heme iron or escape from the protein through a distal histidine gate. The ligand migration into internal cavities induces a structural deformation, which promotes a transient opening of a gate in the $\mathrm{CO}$ migration channel. Such transitional reorganization of the internal cavities is ultimately associated with a change in volume and/or enthalpy and thus can be probed using photothermal techniques. Indeed, $\mathrm{CO}$ photo-dissociation from $\mathrm{Mb}$ has been intensively investigated using PAC by our group and others (Belogortseva et al., 2007; Peters et al., 1992; Vetromile, et al., 2011; Westrick\&Peters, 1990; Westrick et al., 1990) and these results lead to a thermodynamic description of the transient "deoxy intermediate" that is populated upon CO photo-dissociation.

The mechanism of ligand migration in $\mathrm{Hb}$ is more complex, since it is determined by the tertiary structure of individual subunits as well as by the tetramer quaternary structure. Crystallographic data have shown that the structure of the fully unliganded tense $(\mathrm{T})$ state of $\mathrm{Hb}$ and the fully ligated relaxed $(\mathrm{R})$ states differ at both the tertiary and quaternary level (Park et al., 2006). Crystallographic and NMR studies suggest that the fully ligated relaxed state corresponds to the ensemble of conformations with distinct structures (Mueser et al., 2000; Silva et al., 1992). Moreover, Hb interactions with diatomic ligands is modulated by physiological effectors such as protons, chloride, and phosphate ions, and non-physiological ligands including inositol hexakisphosphate (IHP) and bezafibrate (BZF) (Yonetani et al., 2002). Despite a structural homology between $\mathrm{Hb}$ and $\mathrm{Mb}$, the network of internal hydrophobic cavities identified in $\mathrm{Mb}$ is not conserved in $\mathrm{Hb}$ suggesting distinct ligand migration pathways in this protein (Mouawad et al., 2005; Savino et al., 2009). Here we present thermodynamic profiles of CO photo-dissociation from human $\mathrm{Hb}$ in the presence of heterotropic allosteric effectors IHP and BZF. In addition, we include an acoustic study of oxygen photo-dissociation from $\mathrm{Mb}$ that has not been investigated previously using photothermal methods, despite the fact that oxygen is the physiological ligand for $\mathrm{Mb}$. 


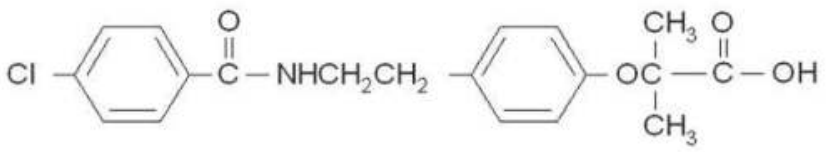

BZF

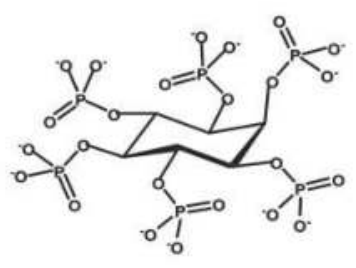

IHP

Scheme 1.

\section{Material and methods}

$\mathrm{Mb}, \mathrm{Hb}$, inositol hexakisphosphate (IHP), and bezafibrate (BZF) were purchased from Sigma-Aldrich and used as received. Fe(III) tetrakis(4-sulfonatophenyl)porphine (Fe(III)4SP) was obtained from Frontier-Scientific Inc. Oxymyoglobin $\left(\mathrm{O}_{2}-\mathrm{Mb}\right)$ samples were prepared by dissolving the protein in $50 \mathrm{mM}$ HEPES buffer $\mathrm{pH}$ 7.0. The sample was then purged with Ar for $10 \mathrm{~min}$ and reduced by addition of a freshly prepared solution of sodium dithionite. The quality of the deoxymyoglobin (deoxyMb) was verified by UV-visible spectroscopy. $\left(\mathrm{O}_{2}-\mathrm{Mb}\right)$ was obtained by bubbling air through deoxyMb sample. The $\mathrm{CO}$ bound hemoglobin sample was prepared by desolving $\mathrm{Hb}$ in $100 \mathrm{mM}$ HEPES buffer $\mathrm{pH} 7.0$ in a 0.5 $x 1 \mathrm{~cm}$ quartz cuvette. The concentration of allosteric effectors was $5 \mathrm{mM}$ for BZF and $1 \mathrm{mM}$ for IHP. The sample was then sealed with a septum cap and purged with Ar for $10 \mathrm{~min}$, reduced with a small amount of sodium dithionite to prepare deoxyhemoglobin (deoxy $\mathrm{Hb})$, and subsequently bubbled with $\mathrm{CO}$ for approximately $1 \mathrm{~min}$. Preparation of $\mathrm{O}_{2}-\mathrm{Mb}$ and $\mathrm{CO}-$ $\mathrm{Hb}$ aducts was checked by UV-vis spectroscopy (Cary50, Varian).

\subsection{Quantum yield determination}

The quantum yield $(\Phi)$ was determined as described previously (Belogortseva et al., 2007). All transient absorption measurements were carried out on $50 \mu \mathrm{M}$ samples in 50 or $100 \mathrm{mM}$ HEPES buffer, $\mathrm{pH} 7.0$, placed in a $2 \mathrm{~mm}$ path quartz cell. The cell was placed into a temperature controlled holder (Quantum Northwest) and the ligand photo-dissociation was triggered using a $532 \mathrm{~nm}$ output from a Nd:YAG laser (Minilite II, Continuum). The probe beam, an output from the Xe arc lamp (200 W, Newport) was propagated through the center of the cell and then focused on the input of a monochromator (Yvon-Jovin ). The intensity of the probe beam was detected using an amplified photodiode (PDA 10A, Thornlabs) and subsequently digitized (Wave Surfer 42Xs, $400 \mathrm{MHz}$ ). The power of the pump beam was kept below $50 \mu \mathrm{J}$ to match the laser power used in photoacoustic measurements. The quantum yield was determined by comparing the change in the sample absorbance at $440 \mathrm{~nm}$ with that of the reference, $\mathrm{CO}$ bound myoglobin of known quantum yield ( $\Phi_{\text {ref }}=0.96$ (Henry et al., 1983)) according to Eq 1:

$$
\Phi=\frac{\Delta \mathrm{A}_{\mathrm{sam}} \Delta \varepsilon_{\mathrm{ref}} \Phi_{\mathrm{ref}}}{\Delta \mathrm{A}_{\mathrm{ref}} \Delta \varepsilon_{\mathrm{sam}}}
$$

where $\Delta \mathrm{A}_{\text {sam }}$ and $\Delta \mathrm{A}_{\text {ref }}$ are the absorbance change of the sample and reference at $440 \mathrm{~nm}$, respectively, and $\Delta \varepsilon_{\text {sam }}$ and $\Delta \varepsilon_{\text {ref }}$ are the change in the extinction coefficient between the $\mathrm{CO}$ bound and reduced form of the sample and the reference, respectively. 


\subsection{Photoacoustic calorimetry}

The photo-acoustic set-up used in our lab was described previously (Miksovska\&Larsen, 2003). Briefly, the sample in a quartz cell was placed in a temperature controlled holder (Quantum Northwest). The $532 \mathrm{~nm}$ output from a Nd:YAG laser (7 ns pulse width , $<50 \mu \mathrm{J}$ power) was shaped using a narrow slit $(100 \mu \mathrm{m})$ and focused on the center of the quartz cell. An acoustic detector $(1 \mathrm{MHz}, \mathrm{RV103}$, Panametrix) was coupled to the side of a quartz cell using a thin layer of honey and the detector output was amplified using an ultrasonic preamplifier (Panametrics 5662). The signal was then stored in a digitizer (Wave Surfer $42 \mathrm{Xs}, 400 \mathrm{MHz}$ ). The data were analyzed using Sound Analysis software (Quantum Northwest).

\subsection{Data analysis}

The excitation of the photocleavable iron-ligand bond in heme proteins generates at least two processes that contribute to the photoacoustic wave: the volume change due to the heat released during the reaction $(\mathrm{Q})$, and the volume change $\left(\Delta \mathrm{V}^{\prime}\right)$ due to the photo-triggered structural changes (including bond cleavage / formation, electrostriction, solvation, etc.). The amplitude of the sample acoustic wave $\left(\mathrm{A}_{\mathrm{sam}}\right)$ can be expressed as:

$$
A_{\text {sam }}=K E_{a}\left(Q \frac{\beta}{\varrho C_{p}}+\Delta V^{\prime}\right)
$$

where $K$ is the instrument response constant, $E_{a}$ is number of Einsteins absorbed, $\beta$ is the expansion coefficient, $\rho$ is the density, and $C_{p}$ is the heat capacity. For water, the $\left(\beta / C_{p} \rho\right)$ term strongly varies with temperature mainly due to the temperature dependence of the $\beta$ term. To evaluate the instrument response constant, the photo-acoustic traces are measured for a reference compound under experimental conditions (laser power, temperature, etc.) identical to those for the sample measurements. We have used Fe(III)4SP as a reference since it is non-fluorescent and photo-chemically stable. The amplitude of the reference acoustic trace can be described as:

$$
A_{\text {ref }}=K E_{a} E_{h v} \frac{\beta}{\varrho C_{p}}
$$

where $\mathrm{E}_{\mathrm{hv}}$ is the energy of a photon at $532 \mathrm{~nm}\left(\mathrm{E}_{\mathrm{hv}}=53.7 \mathrm{kcal} \mathrm{mol}^{-1}\right)$. The amount of heat deposited to the solvent and the non-thermal volume changes can then be determined by measuring the acoustic wave for the sample and the reference for several temperatures and plotting the ratio of the sample and reference acoustic wave $(\phi)$ as a function of $\left(C_{p} \rho / \beta\right)$ according to Eq. 4 :

$$
\frac{A_{\text {sam }}}{A_{\text {ref }}}=\phi=Q+\Delta V^{\prime} \frac{\rho C_{p}}{\beta}
$$

For a multi-step process that exhibits volume and enthalpy changes on the time-scale between $\sim 20 \mathrm{~ns}$ to $5 \mu \mathrm{s}$, the thermodynamic parameters for each individual step and corresponding lifetimes can be determined due to the sensitivity of the acoustic detector to the temporal profile of the pressure change. The time dependent sample acoustic signal $\mathrm{E}(\mathrm{t})_{\text {obs }}$ can be expressed as a convolution of the time dependent function describing the volume change $H(t)$ with the instrument response $T(t)$ function (the reference acoustic wave): 


$$
\begin{gathered}
H(t)=\phi_{1} e^{-\frac{t}{\tau 1}}+\frac{\phi_{2} k_{2}}{\left(k_{2}-k_{1}\right)} e^{-\frac{t}{\tau 1}}-e^{\frac{t}{\tau 2}} \\
E(t)_{o b s}=H(t) \otimes T(t)
\end{gathered}
$$

where $\phi_{1}$ and $\phi_{2}$ correspond to the $\left(\frac{A_{\text {sam }}}{A_{\text {ref }}}\right)$ term in Eq. 4 and the $\tau_{1}$ and $\tau_{2}$ are the lifetime for the first and subsequent step of the reaction, respectively. To retrieve thermodynamic and kinetic parameters, the reference trace is convoluted with the $\mathrm{H}(\mathrm{t})$ function using estimated

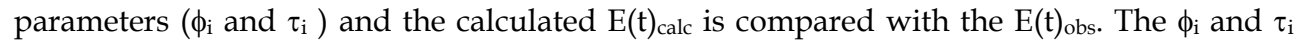
values are varied until a satisfactory fit is obtained in terms of $\chi^{2}$ and autocorrelation function. In practice, the lifetime for the prompt process is fixed to $1 \mathrm{~ns}$, whereas other parameters are allowed to be varied.

For processes that occur with a quantum yield that is temperature dependent in the temperature range used in PAC measurements, the thermodynamic parameters for the fast phase $(\tau<20 \mathrm{~ns})$ are determined by plotting $\left.\left[\mathrm{E}_{\mathrm{hv}}(1-\phi)\right] / \Phi\right]$ versus $\left(\mathrm{C}_{\mathrm{p}} \rho / \beta\right)$ according to $\mathrm{Eq} .7$ and the volume and enthalpy changes for the subsequent steps are obtained by plotting $\left(\phi \mathrm{E}_{\mathrm{hv}} / \Phi\right)$ versus $\left(\mathrm{C}_{\mathrm{p}} \rho / \beta\right)$ according to Eq. 8 (Peters et al., 1992).

$$
\begin{gathered}
\frac{E_{h v}(1-\phi)}{\Phi}=-\Delta H+\Delta V \frac{C_{p} \varrho}{\beta} \\
\frac{\phi E_{h v}}{\Phi}=-\Delta H+\Delta V\left(\frac{C_{p} \rho}{\beta}\right)
\end{gathered}
$$

where $\Delta \mathrm{H}$ and $\Delta \mathrm{V}$ correspond to the reaction enthalpy and volume change, respectively.

\section{Results}

Ligand migration in heme proteins is often described using the sequential three-state model (Henry et al., 1983) shown in Scheme 2. Upon cleavage of the coordination bond between the ligand and heme iron, the ligand is temporarily trapped within the protein matrix and then it either directly rebinds back to the heme iron in the so called "geminate rebinding" or diffuses from the protein matrix into the surrounding solvent. The subsequent bimolecular ligand binding to heme iron occurs on significantly longer time scales, hundreds of microseconds to milliseconds. The quantum yield for the geminate rebinding and for bimolecular association is strongly dependent on the character of the ligand and the protein. For example, $\mathrm{CO}$ rebinds to $\mathrm{Mb}$ predominantly through a bimolecular reaction with quantum yield close to unity $\left(\Phi_{\text {bim }}=0.96\right)$ (Henry et al., 1983), whereas the quantum yield for bimolecular $\mathrm{O}_{2}$ rebinding to heme proteins is significantly lower (Carver et al., 1990; Walda et al., 1994), and NO rebinds predominantly through geminate rebinding (Ye et al., 2002). To determine the thermodynamic parameters from acoustic data, the quantum yields for $\mathrm{CO}$ and $\mathrm{O}_{2}$ bimolecular rebinding to $\mathrm{Hb}$ and $\mathrm{Mb}$, respectively, have to be known. The quantum yield for $\mathrm{O}_{2}$ binding to $\mathrm{Mb}$ was measured in the temperature range from $5{ }^{\circ} \mathrm{C}$ to $35^{\circ} \mathrm{C}$ (Fig. 2) and the values show a weak temperature dependence with the quantum yield decreasing with increasing temperature. At $20{ }^{\circ} \mathrm{C}$ the quantum yield is $0.09 \pm 0.01$ that is within the range of values reported previously $(\Phi=0.057$ (Walda et al., 1994) and $(\Phi=0.12$ (Carver et al., 1990)). We have also measured the quantum yield for CO bimolecular rebinding to $\mathrm{Hb}$, and to $\mathrm{Hb}$ in the presence of effector molecules (Fig. 2). The quantum yield increases linearly with temperature and at $20^{\circ} \mathrm{C}, \mathrm{CO}$ binds to $\mathrm{Hb}$ with quantum yield of 
0.68 and in the presence of IHP and BZF 0.62 and 0.46, respectively. A similar quantum yield for $\mathrm{CO}$ bimolecular rebinding to $\mathrm{Hb}$ was reported previously by Unno et al. $\left(\Phi_{\text {bim }}=0.7\right.$ at $20^{\circ} \mathrm{C}$ ) (Unno et al., 1990) and by Saffran and Gibson $(\Phi=0.7$ for $\mathrm{CO}$ binding to $\mathrm{Hb}$ and $\Phi$ $=0.73$ for $\mathrm{CO}$ association to $\mathrm{Hb}$ in the presence of IHP at $40^{\circ} \mathrm{C}$ ) (Saffran\&Gibson, 1977).

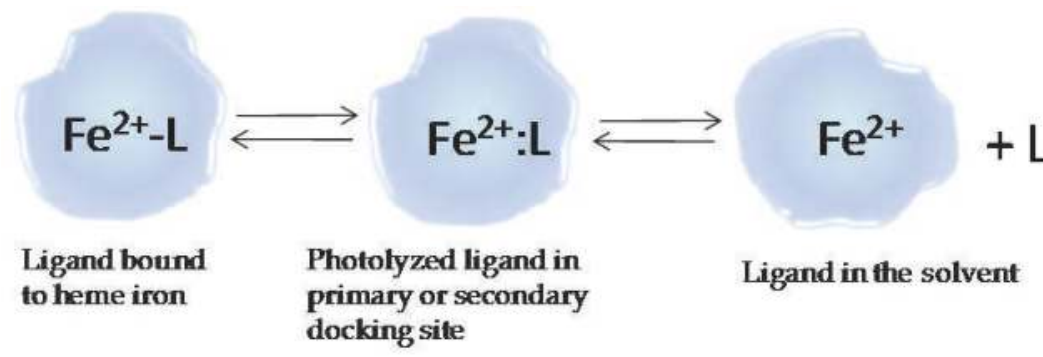

Scheme 2 .

The photo-acoustic traces for $\mathrm{O}_{2}$ dissociation from $\mathrm{Fe}(\mathrm{II}) \mathrm{Mb}$ at $\mathrm{pH} 7.0$ are shown in Fig. 3. At low temperatures $\left(6^{\circ} \mathrm{C}\right.$ to $\left.15^{\circ} \mathrm{C}\right)$, the sample photoacoustic traces show a phase shift with respect to the reference trace indicating the presence of thermodynamic process(es) that occurs between $50 \mathrm{~ns}$ and $\sim 5 \mu \mathrm{s}$. The sample traces were deconvoluted as described in the Materials and Methods section and the $\phi_{i}$ values were plotted as a function of the temperature dependent factor $\left(\mathrm{C}_{\mathrm{p}} \rho / \beta\right)$ (Fig. 4). The extrapolated volume and enthalpy changes are listed in Table 1 . The photo-cleavage of the $\mathrm{Fe}-\mathrm{O}_{2}$ bond is associated with a fast structural relaxation ( $\tau<20 \mathrm{~ns}$ ) forming a transient "deoxy-Mb intermediate". This initial transition is endothermic $\left(\Delta \mathrm{H}=21 \pm 9 \mathrm{kcal} \mathrm{mol}^{-1}\right)$ and leads to a small volume contraction of $-3.0 \pm 0.5 \mathrm{~mL} \mathrm{~mol}^{-1}$. This initial relaxation is followed by $\sim 250 \mathrm{~ns}$ kinetics that exhibit a volume increase of $5.5 \pm 0.4 \mathrm{~mL} \mathrm{~mol}^{-1}$ and a very small enthalpy change of $-8.9 \pm 8.0 \mathrm{kcal}$ $\mathrm{mol}^{-1}$. We associate the initial process with the photo-cleavage of the $\mathrm{Fe}-\mathrm{O}_{2}$ bond. A similar volume decrease of approximately $-3 \mathrm{~mL} \mathrm{~mol}^{-1}$ has been observed previously for the photodissociation of Fe-CO bond in Mb (Westrick\&Peters, 1990; Westrick et al., 1990). The observed volume contraction reflects a fast relaxation of the heme binding pocket including: i) cleavage of the hydrogen bond between the distal histidine and oxygen molecule (Phillips\&Schoenborn, 1981) ii) reorientation of distal residues within the heme binding pocket (Olson et al., 2007), and iii) fast migration of the photo-released ligand into the primary docking site and then into the internal cavities (Xe4 or Xe1) (Hummer et al., 2004). Also, the positive enthalpy change is consistent with the photo-cleavage of $\mathrm{Fe}-\mathrm{O}_{2}$ bond.

The subsequent $250 \mathrm{~ns}$ kinetics may reflect either the nanosecond geminate rebinding of the $\mathrm{O}_{2}$ molecule or the ligand diffusion from the protein matrix into the surrounding solvent. The kinetics for the geminate $\mathrm{O}_{2}$ rebinding were studied on femtosecond timescale by Petrich et al. (Petrich et al., 1988), and on picosecond and nanosecond timescales (Carver et al., 1990; Miller et al., 1996). These studies identified two distinct sub-states of the "deoxyMb" intermediate: a "barrier-less" and a "photolyzable" sub-state. In the "barrierless" sub-state, oxygen rebinds to heme iron on sub-picosecond timescale whereas the oxygen association to the "photolyzable" substate occurs on nanosecond and microsecond timescales. Carver et al. (Carver et al., 1990) have reported the time constant for $\mathrm{O}_{2}$ nanosecond geminate rebinding to be $52 \pm 14 \mathrm{~ns}$ at room temperature. This kinetic step has a lifetime that is comparable to the time resolution of our PAC instrument $(\tau \sim 50 \mathrm{~ns})$ and therefore it was not resolved in this study. The 250 ns step thus corresponds to the $\mathrm{O}_{2}$ escape 


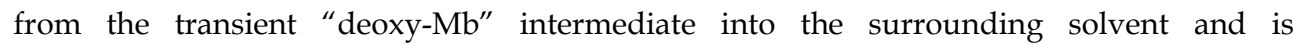
approximately 3 times faster than the rate of the CO escape (Westrick et al., 1990), which suggests that $\mathrm{O}_{2}$ diffuses from the protein matrix through a transient channel with a lower activation barrier than $\mathrm{CO}$. This result is consistent with the transient absorption studies that estimated the rate for $\mathrm{O}_{2}$ release to be approximately two times faster than that for $\mathrm{CO}$ (Carver et al., 1990). Interestingly, a similar time-constant of 200 ns to 300 ns was determined for $\mathrm{CO}$ escape from $\mathrm{Mb}$ at $\mathrm{pH} 3.5$ (Angeloni\&Feis, 2003). At acidic $\mathrm{pH} \mathrm{Mb}$ adopts an open conformation with His 64 displaced toward the solvent giving a direct access to the distal cavity. These data suggest that the reorientation of His 64 may not be a rate limiting step for the $\mathrm{O}_{2}$ escape.
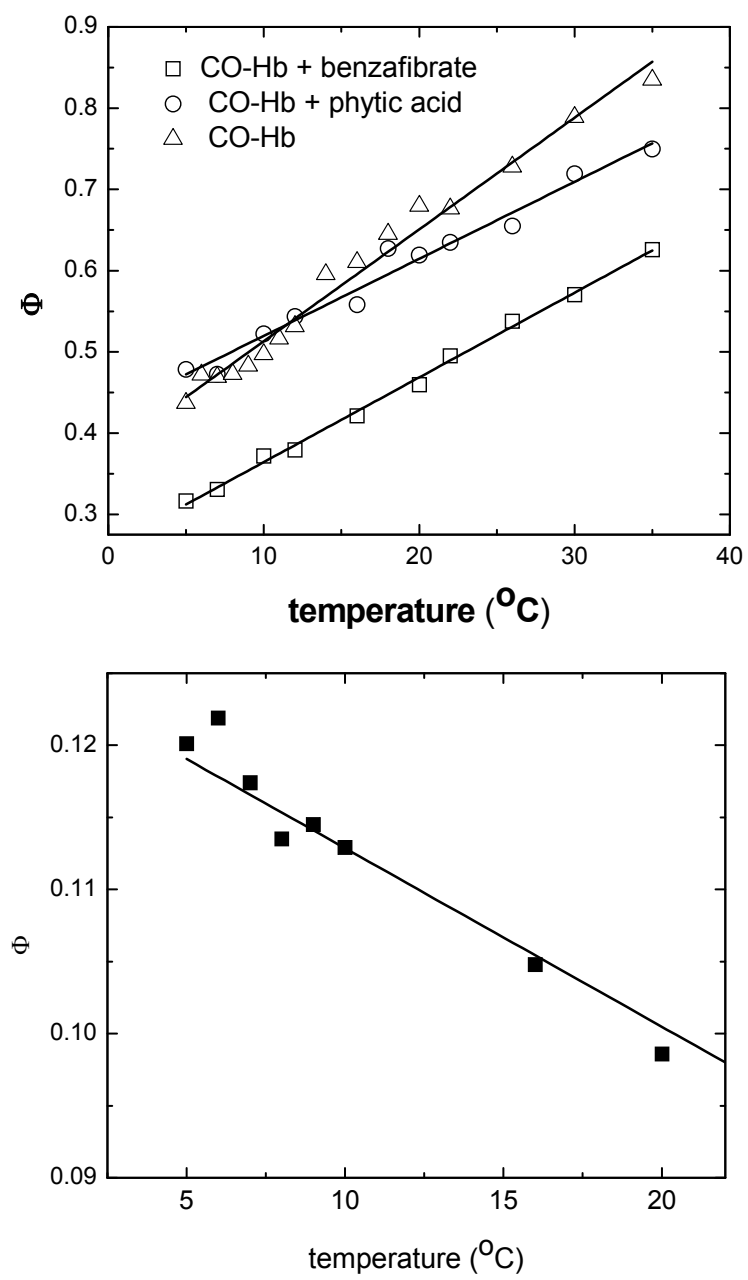

Fig. 2. Quantum yield for bimolecular photo-dissociation of $\mathrm{O}_{2}$ from the $\mathrm{O}_{2}-\mathrm{Mb}$ complex (bottom) and $\mathrm{CO}$ from the $\mathrm{CO}-\mathrm{Hb}$ complex (top) as a function of temperature. The error of quantum yield is \pm 0.05 . The solid line demonstrates the trend. 


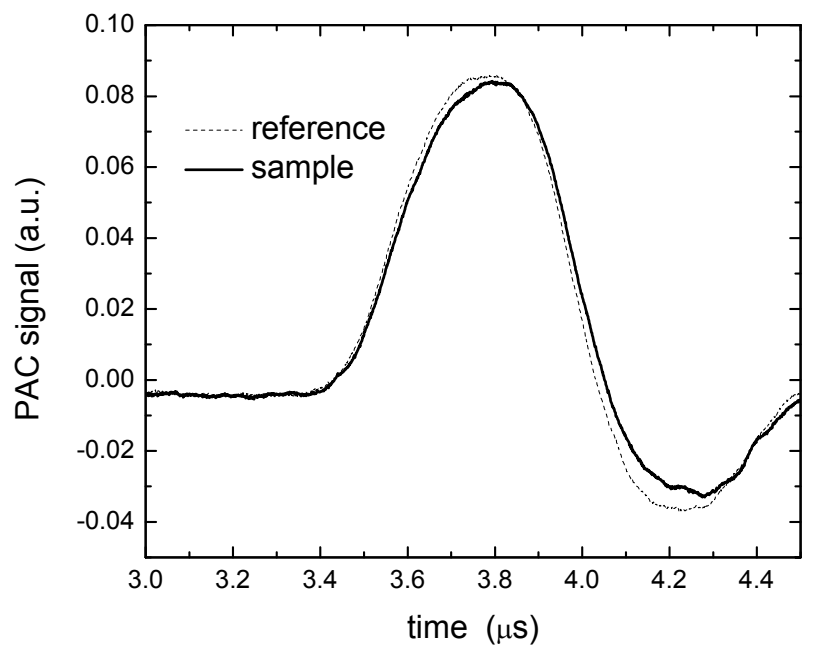

Fig. 3. PAC traces for $\mathrm{O}_{2}$ photo-dissociation from $\mathrm{O}_{2}-\mathrm{Mb}$ complex at $6{ }^{\circ} \mathrm{C}$. Conditions: $40 \mu \mathrm{M}$ $\mathrm{Mb}$ dissolved in $50 \mathrm{mM}$ Hepes buffer $\mathrm{pH}$ 7.0. The absorbance of the reference compound, $\mathrm{Fe}(\mathrm{III}) 4 \mathrm{SP}$, at excitation wavelength of $532 \mathrm{~nm}$ was identical as that of $\mathrm{O}_{2}-\mathrm{Mb}$.

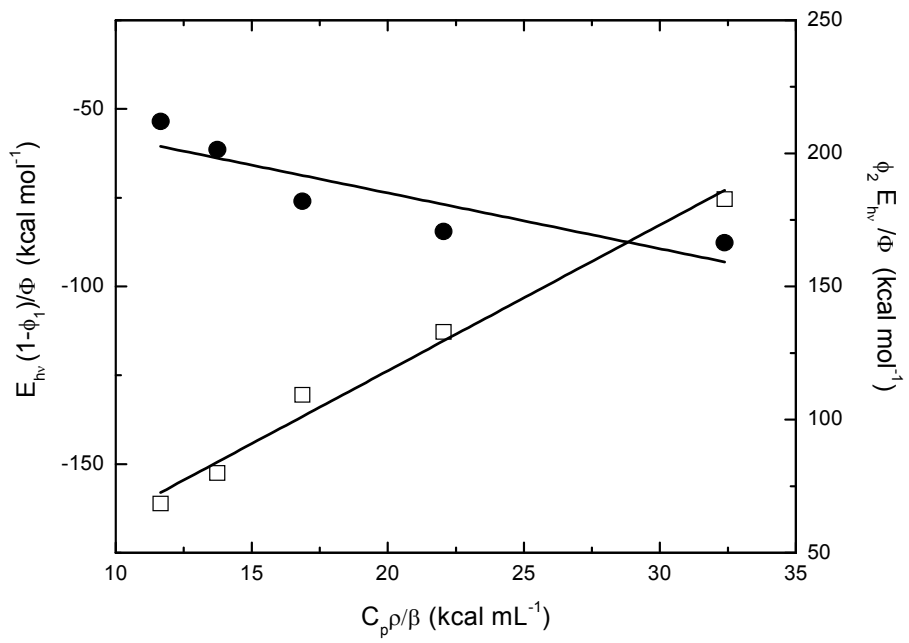

Fig. 4. Plot of the ratio of the acoustic amplitude for the photo-dissociation of the $\mathrm{O}_{2}-\mathrm{Mb}$ complex and the reference compound as a function of $(\mathrm{Cp} \rho / \beta)$ term. $\phi_{1}$ values that correspond to the prompt phase are shown as solid circles and the $\phi_{2}$ values corresponding to the slow phase are shown as open squares. The data were fit with a linear curve and the corresponding volume and enthalpy changes were determined using Eq. 6 and Eq. 7.

The reaction volume change observed for the slow phase includes several factors: i) volume change due to the $\mathrm{O}_{2}$ escape into the surrounding solvent, ii) volume change associated with the heme hydration in deoxy $\mathrm{Mb}$ and iii) volume change due to the structural changes. The 
reaction volume can be expressed as the difference between the partial molar volume of products and reactants according to: $\Delta \mathrm{V}_{\text {slow }}=\mathrm{V}^{\circ} \mathrm{O} 2+\mathrm{V}^{\circ}$ deoxyMb- $\mathrm{V}^{\circ} \mathrm{O} 2-\mathrm{Mb}-\mathrm{V}^{\circ} \mathrm{H} 2 \mathrm{O}$, where $\mathrm{V}^{\circ} \mathrm{O} 2$ is the partial molar volume of oxygen, $\mathrm{V}^{\circ}{ }_{\mathrm{H} 2 \mathrm{O}}$ is the partial molar volume of water, $\mathrm{V}^{\circ}{ }_{\text {deoxyMb }}$ is the partial molar volume of transient "deoxyMb" intermediate and $\mathrm{V}^{\circ} \mathrm{O}-\mathrm{Mb}$ is the partial molar volume of oxy-Mb. Using $\mathrm{V}^{\circ}{ }_{\mathrm{O} 2}=28 \mathrm{~mL}^{-1}$ mol $^{-1}$ (Projahn et al., 1990) and $\mathrm{V}^{\circ}{ }_{\mathrm{H} 2 \mathrm{O}}=15 \mathrm{~mL}$ $\mathrm{mol}^{-1}$ (the partial molar volume of water scaled to the occupancy of water molecule hydrogen bound to distal histidine) (Belogortseva et al., 2007), we estimate that the $\mathrm{O}_{2}$ release from $\mathrm{Mb}$ results in a structural volume change $\left(\mathrm{V}^{\circ}{ }_{\text {doxy } \mathrm{Mb}^{-}} \mathrm{V}^{\circ} \mathrm{O2- \textrm {Mb }}\right)$ of $-7.5 \mathrm{~mL} \mathrm{~mol}-1$. This value is very similar to that reported previously for $\mathrm{CO}$ escape from $\mathrm{Mb}\left(\Delta \mathrm{V}_{\text {structural }}=\right.$ $\mathrm{V}_{\text {doxyMb- }}^{\circ} \mathrm{V}^{\circ} \mathrm{CO}-\mathrm{Mb}=-6 \mathrm{~mL} \mathrm{~mol}^{-1}$ ) (Vetromile, et al., 2011) demonstrating that the overall structural changes accompanying the ligand bound to ligand free transition in $\mathrm{Mb}$ are very similar for both ligands. This is in agreement with the close resemblance of the X-ray structure of both the CO-bound and $\mathrm{O}_{2}$-bound $\mathrm{Mb}$ (Yang\&Phillips Jr, 1996). The small enthalpy change measured for the $250 \mathrm{~ns}$ relaxation $\left(\Delta \mathrm{H}=-8.9 \pm 8.0 \mathrm{kcal} \mathrm{mol}^{-1}\right)$ includes the enthalpy change for $\mathrm{O}_{2}$ solvation $\left(\Delta \mathrm{H}_{\text {solv }}=-2.9 \mathrm{kcal} \mathrm{mol}^{-1}\right.$ (Mills et al., 1979)) and the enthalpy change associated with $\mathrm{H}_{2} \mathrm{O}$ binding to the heme binding pocket $\left(\Delta \mathrm{H}_{\text {solv }}=-7 \mathrm{kcal}\right.$ $\mathrm{mol}^{-1}$ (Vetromile, et al., 2011) indicating that the structural relaxation coupled to the ligand escape from the protein is entropy driven.

The overall enthalpy change for $\mathrm{O}_{2}$ dissociation from $\mathrm{Mb}$ was determined to be $11.6 \pm 8.5$ $\mathrm{kcal} \mathrm{mol}^{-1}$ and this value is in agreement with the value of $10 \mathrm{kcal} \mathrm{mol}^{-1}$ reported previously (Projahn et al., 1990). The overall reaction volume change determined here $\left(\Delta \mathrm{V}_{\text {overall }}=+2.5\right.$ $\left.\mathrm{mL} \mathrm{mol}{ }^{-1}\right)$ is somewhat larger than the reaction volume change determined from the measurement of the equilibrium constant as a function of pressure $\left(\Delta \mathrm{V}=-2.9 \mathrm{~mL} \mathrm{~mol} \mathrm{~m}^{-1}\right)$ (Hasinoff, 1974) and significantly smaller than the reaction volume change determined as a difference between the activation volume for oxygen binding and dissociation from $\mathrm{Mb}$ that was reported to be $18 \mathrm{~mL} \mathrm{~mol}^{-1}$ (Projahn et al., 1990). Unlike photoacoustic studies that allow for reaction volume determination at ambient pressure, the high pressure measurements of equilibrium constant and/or rate constants (to determine activation volumes) may cause a pressure induced protein denaturation and/or structural changes, which may influence the magnitude of reaction volume changes in high pressure studies.

\begin{tabular}{lll}
\hline & $\boldsymbol{\Delta V}\left(\mathbf{m L ~ m o l}^{-1}\right)$ & $\Delta \mathbf{H}\left(\mathbf{k c a l ~ m o l}^{-1}\right)$ \\
\hline Fast phase & $-3.0 \pm 0.5$ & $20.5 \pm 8.5$ \\
\hline Slow phase & $5.5 \pm 0.4$ & $-8.9 \pm 8.0$ \\
\hline
\end{tabular}

Table 1. Volume and enthalpy changes associated with $\mathrm{O}_{2}$ dissociation from $\mathrm{Mb}$ in the temperature range $6-10^{\circ} \mathrm{C}$.

We have also probed the thermodynamic parameters associated with the $\mathrm{CO}$ photodissociation from $\mathrm{Hb}$ and the impact of the binding of BZF and IHP on the thermodynamics associated with the ligand migration between the heme binding pocket and surrounding solvent. The photo-acoustic traces for $\mathrm{CO}$ photo-dissociation from $\mathrm{Hb}$ are shown in Fig. 5. The sample and the reference acoustic wave overlay in phase indicating that the observed thermodynamic processes take place within 50 ns upon photo-dissociation, which is consistent with the fast $\mathrm{CO}$ diffusion from the heme matrix into the surrounding solvent. 
The fast ligand escape from the heme binding pocket was observed in the presence of effectors (data not shown). Previous transient absorption studies showed that the CO photo-release from the fully ligated $\mathrm{R}$-state $\mathrm{Hb}$ is followed by three relaxations with lifetimes of $50 \mathrm{~ns}, 1 \mu \mathrm{s}$, and $20 \mu \mathrm{s}$ that were assigned to the unimolecular geminate rebinding, the tertiary structural relaxation, and the $\mathrm{R} \rightarrow \mathrm{T}$ quaternary change, respectively (Goldbeck et al., 1996). The geminate rebinding occurs too fast to be resolved by our PAC detector, whereas the $20 \mu \mathrm{s} R \rightarrow \mathrm{T}$ transition, which strongly depends on the extent of heme ligation, is too slow to be resolved in PAC measurements. The $1 \mu$ s relaxation is within the time-window accessible by our detection system, however we were unable to resolve this step. Since this relaxation was observed as a small perturbation of the deoxy-Soret band (Goldbeck et al., 1996), it may reflect the structural relaxation localized within the vicinity of the heme binding pocket, which does not lead to measurable volume and enthalpy changes.

The volume and enthalpy changes associated with the diffusion of the photo-dissociated ligand to the surrounding solvent can be determined from the plot of the ratio of the amplitude of the acoustic trace for $\mathrm{CO}$ photo-dissociation from $\mathrm{Hb}$ and the reference as a function of temperature according to Eq. 7 (Fig. 6). The extrapolated thermodynamic values

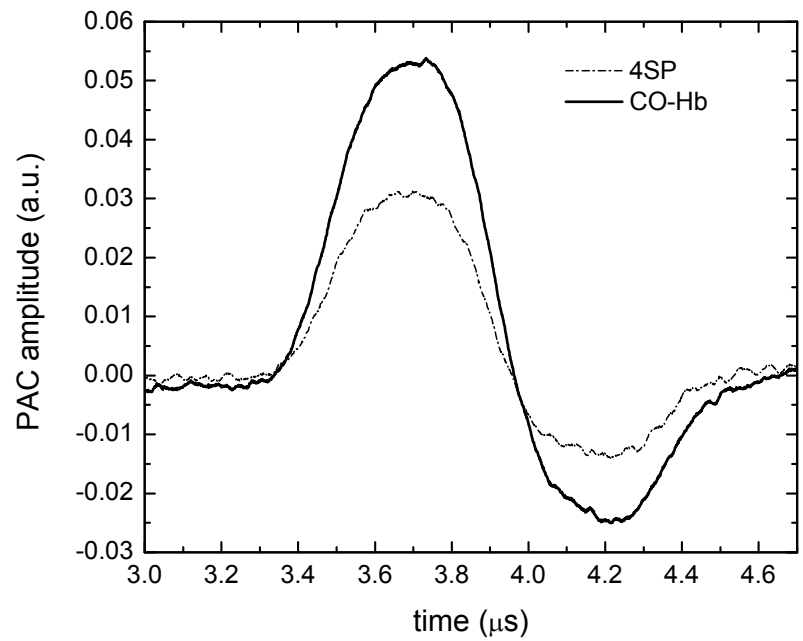

Fig. 5. PAC traces for the $\mathrm{CO}$ photo-dissociation from the $\mathrm{CO}-\mathrm{Hb}$ complex and the reference compound Fe(III)4SP. Conditions: $40 \mu \mathrm{M} \mathrm{Hb}$ in $100 \mathrm{mM}$ HEPES buffer $\mathrm{pH} 7.0$ and $20^{\circ} \mathrm{C}$. The absorbance of the reference compound matched the absorbance of the sample at 532 nm.

are shown in Table 2. The $\mathrm{CO}$ photo-release from $\mathrm{Hb}$ is associated with a positive volume change of $21.5 \pm 0.9 \mathrm{~mL} \mathrm{~mol}^{-1}$ and enthalpy change of $19.4 \pm 1.2 \mathrm{kcal} \mathrm{mol}^{-1}$. These results are in agreement with the thermodynamic parameters reported previously by Peters et al: $\Delta \mathrm{V}=23.4 \pm 0.5 \mathrm{~mL} \mathrm{~mol}^{-1}$ and $\Delta \mathrm{H}=18.0 \pm 2.9 \mathrm{kcal} \mathrm{mol}^{-1}$ (Peters et al., 1992). Since the laser power used in this study was kept below $50 \mu \mathrm{J}$, the low level of photo-dissociation was achieved that corresponds to $1 \mathrm{CO}$ molecule per hemoglobin photo-released. Thus the observed thermodynamic parameters reflect the transition between fully ligated $(\mathrm{CO})_{4} \mathrm{Hb}$ 
and triple ligated $(\mathrm{CO})_{3} \mathrm{Hb}$. Consequently, the observed reaction enthalpy corresponds to the enthalpy change due to the cleavage of the Fe-CO bond $\left(\Delta \mathrm{H}_{\mathrm{Fe}-\mathrm{CO}}=17.5 \mathrm{kcal} \mathrm{mol}^{-1}\right.$ (Leung et al., 1987; Miksovska et al., 2005)), the enthalpy change due to the solvation of a CO molecule $\left(\Delta \mathrm{H}_{\text {solv }}=2.6 \mathrm{kcal} \mathrm{mol}^{-1}\right.$ (Leung et al., 1987)), the enthalpy change of structural relaxation associated with the ligand release from the protein matrix, and enthalpy of the distal pocket hydration. The occupancy of water molecules in the distal pocket of deoxyHb was determined to be significantly lower than that in $\mathrm{Mb}(\sim 0.64$ for the $\mathrm{Hb} \alpha$-chain and $\sim 0.33$ for the $\mathrm{Hb} \beta$-chain (Esquerra et al., 2010)). Using an average occupancy of 0.48 , we estimate that the distal pocket hydration contributes to the overall enthalpy change by $\sim-3 \mathrm{kcal} \mathrm{mol}^{-1}$ (Vetromile, et al., 2011). Therefore, the structural relaxation coupled to the $\mathrm{CO}$ dissociation and diffusion into the surrounding solvent is accompanied by a small enthalpy change of $2 \mathrm{kcal} \mathrm{mol}^{-1}$.

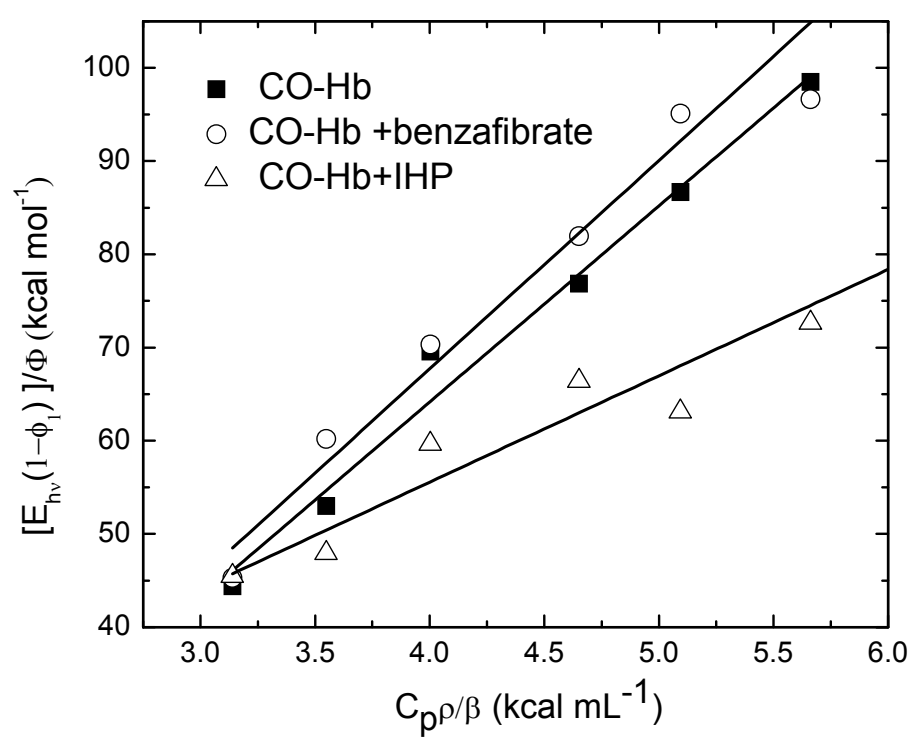

Fig. 6. The plot of the ratio of the acoustic amplitude for the $\mathrm{CO}$ photo-dissociation from the $\mathrm{CO}-\mathrm{Hb}$ complex and the reference compound as a function of the temperature dependent factor $\left(C_{p} \rho / \beta\right)$ term. The reaction volume and enthalpy changes were extrapolated according to Eq. 5

Analogous to $\mathrm{O}_{2}$ photo-release from $\mathrm{Mb}$, the observed reaction volume change for $\mathrm{CO}$ photorelease from $\mathrm{Hb}, \Delta \mathrm{V}=21.5 \mathrm{~mL} \mathrm{~mol}^{-1}$, can be expressed as: $\Delta \mathrm{V}=\mathrm{V}^{\circ} \mathrm{CO}+\mathrm{V}^{\circ}{ }_{(\mathrm{CO}) 3 \mathrm{Hb}}-$ $\mathrm{V}^{\circ}{ }_{(\mathrm{CO}) 4 \mathrm{Hb}}-\mathrm{V}^{\circ}{ }_{\mathrm{H} 2 \mathrm{O}}$, where $\mathrm{V}^{\circ} \mathrm{CO}$ is the partial molar volume of $\mathrm{CO}$ and $\mathrm{V}^{\circ}{ }_{(\mathrm{CO}) 3 \mathrm{Hb}}$ and $\mathrm{V}^{\circ}{ }_{(\mathrm{CO}) 4}$ $\mathrm{Hb}$ are the partial molar volume of $(\mathrm{CO})_{3} \mathrm{Hb}$ and $(\mathrm{CO})_{4} \mathrm{Hb}$, respectively. Using $\mathrm{V}^{\circ} \mathrm{CO}=35$ $\mathrm{mL}$ mol-1 (Projahn et al., 1990) and $\mathrm{V}^{\circ}{ }_{\mathrm{H} 2 \mathrm{O}}=9 \mathrm{~mL} \mathrm{~mol}^{-1}$ (partial molar volume of water scaled by the average occupancy of the $\mathrm{Hb}$ chain), we estimate that upon release of one $\mathrm{CO}$ molecule per $\mathrm{Hb}$, the protein undergoes a small contraction of $-7 \mathrm{~mL} \mathrm{~mol}^{-1}$. The small volume change observed here is consistent with the minor structural changes due to deligation of $\mathrm{Hb}$ in the $\mathrm{R}$-state as observed in the X-ray structure that are predominantly 
localized in the the $\alpha$-chain and include reposition of the F-helix and shift of the EF and CD corner (Wilson et al., 1996).

\begin{tabular}{lcc}
\hline & $\Delta$ Hprompt (kcal mol-1) & $\Delta$ V prompt (mL mol-1) \\
\hline $\mathrm{CO}-\mathrm{Hb}$ & $19.4 \pm 1.2$ & $21.5 \pm 0.9$ \\
\hline $\mathrm{CO}-\mathrm{Hb}+\mathrm{BZF}$ & $21.7 \pm 7.9$ & $22.3 \pm 1.7$ \\
\hline $\mathrm{CO}-\mathrm{Hb}+\mathrm{IHP}$ & $-9.9 \pm 6.1$ & $11.4 \pm 1.3$ \\
\hline
\end{tabular}

Table 2. Volume and enthalpy changes associated with CO photo-dissociation from $\mathrm{Hb}$.

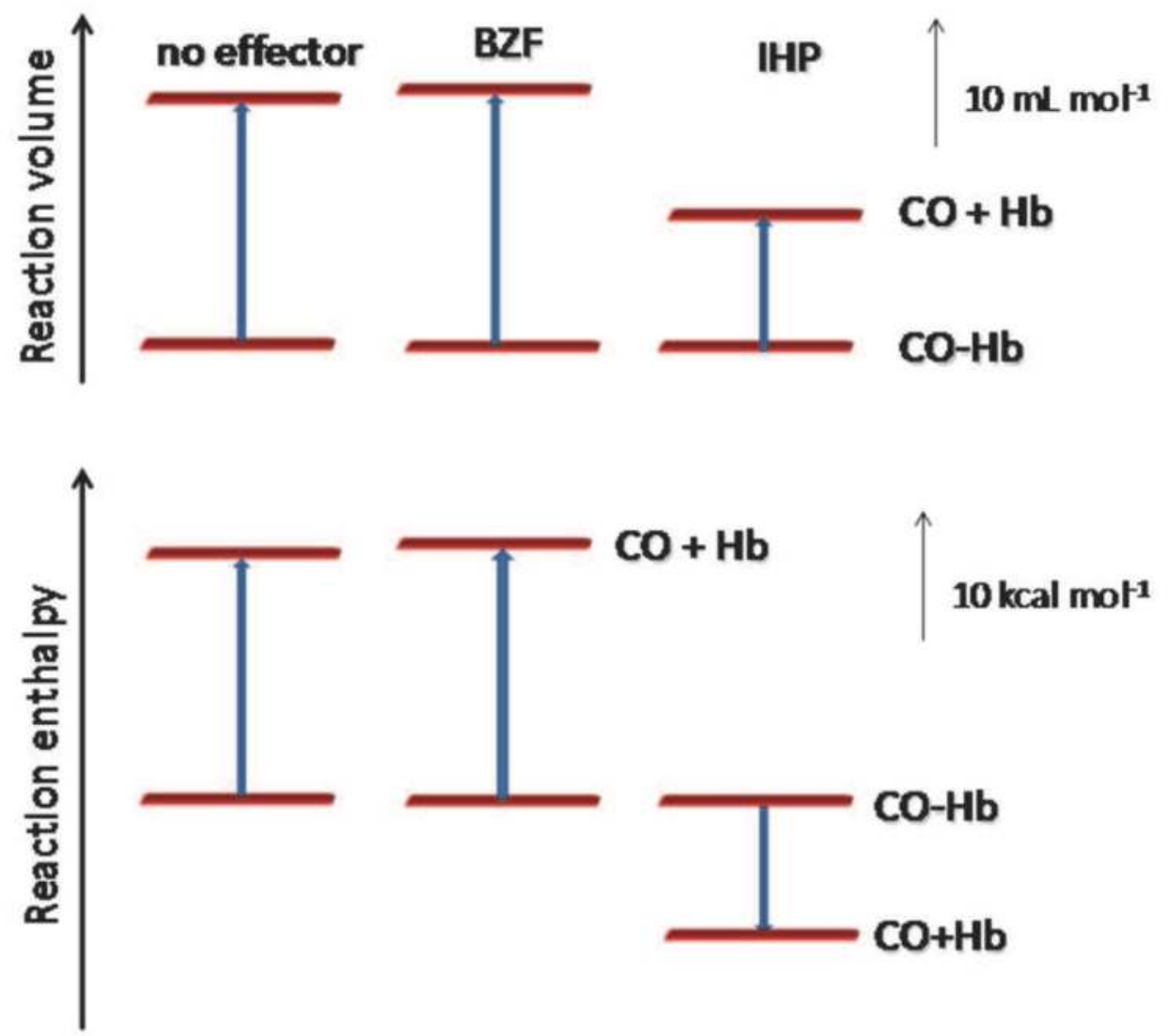

Fig. 7. The thermodynamic profile for $\mathrm{CO}$ photo-dissociation from $\mathrm{Hb}$ in the absence of effector and in the presence of BZF and IHP. 
We have also determined volume and enthalpy changes associated with the CO photodissociation from $\mathrm{Hb}$ in the presence of heterogenous effectors BZT and IHP (Fig. 6) and the thermodynamic profiles for $\mathrm{CO}$ photo-dissociation from $\mathrm{CO}-\mathrm{Hb}$ complex in the presence and absence of effectors are presented in Fig.7 . Both effectors bind to $\mathrm{Hb}$ in the T-state and R-state and modulate the interaction of $\mathrm{Hb}$ with diatomic ligands (Coletta et al., 1999b; Marden et al., 1990). For example, the binding of BZF or IHP to CO-Hb complex decreases the $\mathrm{CO}$ association rate approximately four or eight times, respectively (Marden et al., 1990), and decreases the affinity of $\mathrm{R}$ state deoxy-Hb for oxygen (Tsuneshige et al., 2002). Coletta et al (Coletta et al., 1999a) have reported that simultaneous binding or IHP and BZF effectors to $\mathrm{Hb}$ at ambient pressure leads to the $\mathrm{Hb}$ intermediate with tertiary $\mathrm{T}$-like structure in the quaternary R-conformation. Recently, using NMR spectroscopy Song et al. have shown that binding of IHP to the fully ligated $\mathrm{Hb}$ increase the conformational fluctuation of the R-state in both the $\alpha$ - and $\beta$-chain (Song et al., 2008).

The photoacoustic data presented here show that BZF binding to $\mathrm{CO}-\mathrm{Hb}$ complex does not impact the reaction volume and enthalpy changes associated with $\mathrm{CO}$ photo-release. The crystal structure of horse $\mathrm{CO}-\mathrm{Hb}$ in complex with BZF indicates that the structural changes due to BZF association to fully ligated $\mathrm{Hb}$ are localized in the $\alpha$-subunits (Shibayama et al., 2002). BZF binds to the surface of each $\alpha$-chain E-helix and decreases the distance between the heme iron and distal His and its binding site is surrounded by hydrophobic residues such as Ala 65, Leu 68, Leu 80 and Leu 83 (Shibayama et al., 2002). Such minor structural changes caused by BZF association are unlikely to alter the overall structural volume and enthalpy changes associated with the $\mathrm{CO}$ photo-release. However, due to the lower solubility of BZF, the effector concentration used is this study was $5 \mathrm{mM}$ that results in a $\mathrm{Hb}$ fractional saturation of 0.25 (using $\mathrm{K}_{\mathrm{D}}$ of $15 \mathrm{mM}$ (Ascenzi et al., 1993)). Such lower fractional saturation may prevent detection of BZF induced changes in $\mathrm{Hb}$ conformational dynamics.

On the other hand, the binding of IHP has a significant impact on the observed volume and enthalpy changes (Table 2). The reaction volume decreases by $10 \mathrm{~mL} \mathrm{~mol}^{-1}$ and the enthalpy change is more exothermic by nearly $30 \mathrm{kcal}^{\mathrm{mol}-1}$ compared to the thermodynamic parameters determined in the absence of effector molecules. Such negative reaction volume and exothermic enthalpy change indicates that electrostriction of solvent molecules caused by reorganization of salt bridges or redistribution of charges on protein surface contributes to the overall reaction volume and enthalpy change associated with the CO photo-release. Indeed, IHP interacts with charged residues along the $\mathrm{Hb}$ central cavity. At the $\mathrm{Hb} \mathrm{T}$-state, the IHP binding site is located at the interface of the $\beta$-chains involving Val 1, His2, Lys 82 and His 141 from each chain (Riccio et al., 2001); whereas at the R-state $\mathrm{Hb}$, the IHP molecule interacts with the charged residues Lys 99 and Arg 141 from each $\alpha$-chain (Laberge et al., 2005). In the absence of the X-ray structure of IHP bound fully ligated and partially photolyzed $\mathrm{CO}-\mathrm{Hb}$, it is difficult to point out the factors that contribute to the observed volume and enthalpy changes on the molecular level. Arg 141 forms a salt bridge with Asp 126 in the T-state deoxy $\mathrm{Hb}$ that is absent in the fully ligated R- state (Park et al., 2006). We speculate that the transition between the fully ligated $(\mathrm{CO})_{4} \mathrm{Hb}$ and partially ligated $(\mathrm{CO})_{3} \mathrm{Hb}$ may be associated with a repositioning of the Arg 141 side chain leading to a partial exposure of either the IHP molecule and/or the Arg 141 side chain to the surrounding solvent molecules. Also, the 
ligand photo-release may be associated with the repositioning of the IHP molecule within the $\mathrm{Hb}$ central cavity. Based on a molecular dynamics simulation of IHP binding sides in south polar skua deoxyHb, an IHP migration pathway connecting the binding site at the interface between the $\alpha$-chains and the second binding site located between the $\beta$-chains was proposed suggesting that IHP interactions with $\mathrm{Hb}$ are dynamic and involve numerous positively charged residues situated along the central cavity (Riccio et al., 2001). Therefore, CO photo-release may trigger relocation of IHP within the central cavity resulting in larger exposure of IHP phosphate groups and/or charged amino acid residues and concomitant electrostriction of solvent molecules.

\section{Conclusion}

The photoacoustic data for the ligand photo-dissociation from $\mathrm{Mb}$ shows that the structural volume changes associated with the $\mathrm{O}_{2}$ diffusion from the $\mathrm{Mb}$ active site are similar to those determined previously for $\mathrm{CO}$ in agreement with the crystallographic data. On the other hand, the time constant for $\mathrm{O}_{2}$ escape from the distal pocket to the surrounding solvent is two to three time faster than that for $\mathrm{CO}$ suggesting a distinct migration pathway for diatomic ligands in $\mathrm{Mb}$. Our PAC study also indicates that IHP binding to $\mathrm{Hb}-\mathrm{CO}$ complex alters the volume and enthalpy changes associated with the $\mathrm{CO}$ photo-dissociation from the heme iron indicating that the transition between the fully ligated $(\mathrm{CO})_{4} \mathrm{Hb}$ and partially ligated $(\mathrm{CO})_{3} \mathrm{Hb}$ complex is associated with the reorientation of IHP molecule within the central cavity and/ or charged amino acid residues interacting with IHP.

\section{Acknowledgement}

This work was supported by J. \& E. Biomedical Research Program (Florida Department of Health) and National Science Foundation (MCB 1021831).

\section{References}

Angeloni, L.\&Feis, A. (2003). Protein relaxation in the photodissociation of myoglobin-CO complexes. Photochem. Photobiol. Sci, 2, 7, pp. 730-740, 1474-905X

Ascenzi, P., Bertollini, A., Santucci, R., Amiconi, G., Coletta, M., Desideri, A., Giardina, B., Polizio, F.\&Scatena, R. (1993). Cooperative effect of inositol hexakisphosphate, bezafibrate, and clofibric acid on the spectroscopic properties of the nitric oxide derivative of ferrous human hemoglobin. J. Inorg. Biochem., 50, 4, pp. 263-272, $0162-$ 0134

Belogortseva, N., Rubio, M., Terrell, W.\&Miksovska, J. (2007). The contribution of heme propionate groups to the conformational dynamics associated with $\mathrm{CO}$ photodissociation from horse heart myoglobin. J. Inorg. Biochem., 101, 7, pp. 977-986, 0162-0134

Bossa, C., Anselmi, M., Roccatano, D., Amadei, A., Vallone, B., Brunori, M.\&Di Nola, A. (2004). Extended Molecular Dynamics Simulation of the Carbon Monoxide Migration in Sperm Whale Myoglobin. Biophys. J., 86, 6, pp. 3855-3862, 0006-3495 
Carver, T. E., Rohlfs, R. J., Olson, J. S., Gibson, Q. H., Blackmore, R. S., Springer, B. A.\&Sligar, S. G. (1990). Analysis of the kinetic barriers for ligand binding to sperm whale myoglobin using site-directed mutagenesis and laser photolysis techniques. J. Biol. Chem., 265, 32, pp. 20007-20020,

Coletta, M., Angeletti, M., Ascenzi, P., Bertollini, A., Della Longa, S., De Sanctis, G., Priori, A. M., Santucci, R.\&Amiconi, G. (1999a). Coupling of the Oxygen-linked Interaction Energy for Inositol Hexakisphosphate and Bezafibrate Binding to Human HbA0. J. Biol. Chem., 274, 11, pp. 6865-6874,

Coletta, M., Angeletti, M., Ascone, I., Boumis, G., Castellano, A. C., Dell Ariccia, M., Della Longa, S., De Sanctis, G., Priori, A. M., Santucci, R., Feis, A.\&Amiconi, G. (1999b). Heterotropic Effectors Exert More Significant Strain on Monoligated than on Unligated Hemoglobin. Biophys. J., 76, 3, pp. 1532-1536, 0006-3495

Esquerra, R. M., Lopez-Pena, I., Tipgunlakant, P., Birukou, I., Nguyen, R. L., Soman, J., Olson, J. S., Kliger, D. S.\&Goldbeck, R. A. (2010). Kinetic spectroscopy of heme hydration and ligand binding in myoglobin and isolated hemoglobin chains: an optical window into heme pocket water dynamics. Phys. Chem. Chem. Phys., 12, 35, pp. 10270-10278, 1463-9076

Gensch, T.\&Viappiani, C. (2003). Time-resolved photothermal methods: accessing timeresolved thermodynamics of photoinduced processes in chemistry and biology. Photoch. Photobiol. Sci., 2, 7, pp. 699-721, 1474-905X

Gibson, Q. H., Olson, J. S., McKinnie, R. E.\&Rohlfs, R. J. (1986). A kinetic description of ligand binding to sperm whale myoglobin. J. Biol. Chem., 261, 22, pp. 10228-10239,

Goldbeck, R. A., Paquette, S. J., Björling, S. C.\&Kliger, D. S. (1996). Allosteric Intermediates in Hemoglobin. 2. Kinetic Modeling of HbCO Photolysis. Biochemistry, 35, 26, pp. 8628-8639, 0006-2960

Hasinoff, B. B. (1974). Kinetic activation volumes of the binding of oxygen and carbon monoxide to hemoglobin and myoglobin studied on a high-pressure laser flash photolysis apparatus. Biochemistry, 13, 15, pp. 3111-3117, 0006-2960

Henry, E. R., Sommer, J. H., Hofrichter, J., Eaton, W. A.\&Gellert, M. (1983). Geminate recombination of carbon monoxide to myoglobin. J. Mol. Biol., 166, 3, pp. 443-451, 0022-2836

Henzler-Wildman, K. A., Lei, M., Thai, V., Kerns, S. J., Karplus, M.\&Kern, D. (2007). A hierarchy of timescales in protein dynamics is linked to enzyme catalysis. Nature, 450, 7171, pp. 913-916, 1476-4687

Hummer, G., Schotte, F.\&Anfinrud, P. A. (2004). Unveiling functional protein motions with picosecond x-ray crystallography and molecular dynamics simulations.Proc. Natl. Acad. Sci. U.S.A., 101, 43, pp. 15330-15334,

Laberge, M., Kövesi, I., Yonetani, T.\&Fidy, J. (2005). R-state hemoglobin bound to heterotropic effectors: models of the DPG, IHP and RSR13 binding sites. FEBS Lett., 579, 3, pp. 627-632, 0014-5793

Leung, W. P., Cho, K. C., Chau, S. K.\&Choy, C. L. (1987). Measurement of the protein-ligand bond energy of carboxymyoglobin by pulsed photoacoustic calorimetry. Chem. Phys. Lett., 141, 3, pp. 220-224, 0009-2614 
Marden, M. C., Bohn, B., Kister, J.\&Poyart, C. (1990). Effectors of hemoglobin. Separation of allosteric and affinity factors. Biophys. J., 57, 3, pp. 397-403, 0006-3495

Miksovska, J.\&Larsen, R. W. (2003). Structure-function relationships in metalloproteins. Methods Enzymol, 360, pp. 302-329, 0076-6879

Miksovska, J., Norstrom, J.\&Larsen, R. W. (2005). Thermodynamic profiles for CO photodissociation from heme model compounds: effect of proximal ligands. Inorg Chem, 44, 4, pp. 1006-1014, 0020-1669

Milani, M., Nardini, M., Pesce, A., Mastrangelo, E.\&Bolognesi, M. (2008). Hemoprotein timeresolved X-ray crystallography. IUBMB Life, 60, 3, pp. 154-158, 1521-6551

Miller, L. M., Patel, M.\&Chance, M. R. (1996). Identification of Conformational Substates in Oxymyoglobin through the pH-Dependence of the LowTemperature Photoproduct Yield. J. Am. Chem. Soc., 118, 19, pp. 4511-4517, 0002-7863

Mills, F. C., Ackers, G. K., Gaud, H. T.\&Gill, S. J. (1979). Thermodynamic studies on ligand binding and subunit association of human hemoglobins. Enthalpies of binding $\mathrm{O} 2$ and $\mathrm{CO}$ to subunit chains of hemoglobin A. J. Biol. Chem., 254, 8, pp. 2875-2880,

Mouawad, L., Maréchal, J.-D.\&Perahia, D. (2005). Internal cavities and ligand passageways in human hemoglobin characterized by molecular dynamics simulations. Biochim. Biophys. Acta, 1724, 3, pp. 385-393, 0304-4165

Mueser, T. C., Rogers, P. H.\&Arnone, A. (2000). Interface sliding as illustrated by the multiple quaternary structures of liganded hemoglobin. Biochemistry, 39, 50, pp. 15353-15364, 0006-2960

Olson, J. S., Soman, J.\&Phillips, G. N. (2007). Ligand pathways in myoglobin: A review of trp cavity mutations. IUBMB Life, 59, 8-9, pp. 552-562, 1521-6551

Park, S.-Y., Yokoyama, T., Shibayama, N., Shiro, Y.\&Tame, J. R. H. (2006). $1.25 \AA$ A Resolution Crystal Structures of Human Haemoglobin in the Oxy, Deoxy and Carbonmonoxy Forms. J. Mol. Biol., 360, 3, pp. 690-701, 0022-2836

Peters, K. S., Watson, T.\&Logan, T. (1992). Photoacoustic calorimetry study of human carboxyhemoglobin. J. Am. Chem. Soc., 114, 11, pp. 4276-4278, 0002-7863

Petrich, J. W., Poyart, C.\&Martin, J. L. (1988). Photophysics and reactivity of heme proteins: a femtosecond absorption study of hemoglobin, myoglobin, and protoheme. Biochemistry, 27, 11, pp. 4049-4060, 0006-2960

Phillips, S. E. V.\&Schoenborn, B. P. (1981). Neutron diffraction reveals oxygen-histidine hydrogen bond in oxymyoglobin. Nature, 292, 5818, pp. 81-82,

Projahn, H. D., Dreher, C.\&Van Eldik, R. (1990). Effect of pressure on the formation and deoxygenation kinetics of oxymyoglobin. Mechanistic information from a volume profile analysis. J. Am. Chem. Soc., 112, 1, pp. 17-22, 0002-7863

Riccio, A., Tamburrini, M., Giardina, B.\&di Prisco, G. (2001). Molecular Dynamics Analysis of a Second Phosphate Site in the Hemoglobins of the Seabird, South Polar Skua. Is There a Site-Site Migratory Mechanism along the Central Cavity? Biophys. J., 81, 4, pp. 1938-1946, 0006-3495 
Saffran, W. A.\&Gibson, Q. H. (1977). Photodissociation of ligands from heme and heme proteins. Effect of temperature and organic phosphate. J. Biol. Chem., 252, 22, pp. 7955-7958,

Savino, C., Miele, A. E., Draghi, F., Johnson, K. A., Sciara, G., Brunori, M.\&Vallone, B. (2009). Pattern of cavities in globins: The case of human hemoglobin. Biopolymers, 91, 12, pp. 1097-1107, 1097-0282

Shibayama, N., Miura, S., Tame, J. R. H., Yonetani, T.\&Park, S.-Y. (2002). Crystal Structure of Horse Carbonmonoxyhemoglobin-Bezafibrate Complex at $1.55-\AA$ Resolution. J. Biol. Chem., 277, 41, pp. 38791-38796,

Silva, M. M., Rogers, P. H.\&Arnone, A. (1992). A third quaternary structure of human hemoglobin A at 1.7-A resolution. J. Biol. Chem., 267, 24, pp. 17248-17256,

Song, X.-j., Simplaceanu, V., Ho, N. T.\&Ho, C. (2008). Effector-Induced Structural Fluctuation Regulates the Ligand Affinity of an Allosteric Protein: Binding of Inositol Hexaphosphate Has Distinct Dynamic Consequences for the $\mathrm{T}$ and $\mathrm{R}$ States of Hemoglobin. Biochemistry, 47, 17, pp. 4907-4915, 0006-2960

Šrajer, V., Ren, Z., Teng, T.-Y., Schmidt, M., Ursby, T., Bourgeois, D., Pradervand, C., Schildkamp, W., Wulff, M.\&Moffat, K. (2001). Protein Conformational Relaxation and Ligand Migration in Myoglobin: A Nanosecond to Millisecond Molecular Movie from Time-Resolved Laue X-ray Diffraction†. Biochemistry, 40, 46, pp. 1380213815, 0006-2960

Tsuneshige, A., Park, S.\&Yonetani, T. (2002). Heterotropic effectors control the hemoglobin function by interacting with its $\mathrm{T}$ and $\mathrm{R}$ states--a new view on the principle of allostery. Biophys. Chem., 98, 1-2, pp. 49-63, 0301-4622

Unno, M., Ishimori, K.\&Morishima, I. (1990). High-pressure laser photolysis study of hemoproteins. Effects of pressure on carbon monoxide binding dynamics for Rand T-state hemoglobins. Biochemistry, 29, 44, pp. 10199-10205, 0006-2960

Vetromile, C. M., Miksovska, J.\&Larsen, R. W. (2011). Time resolved thermodynamics associated with ligand photorelease in heme peroxidases and globins: Open access channels versus gated ligand release. Biochim. Biophys. Acta, pp. 1570-9639

Walda, K. N., Liu, X. Y., Sharma, V. S.\&Magde, D. (1994). Geminate recombination of diatomic ligands CO, O2, NO with myoglobin Biochemistry, 33, pp. 2198-2209,

Westrick, J. A.\&Peters, K. S. (1990). A photoacoustic calorimetric study of horse myoglobin. Biophys. Chem., 37, 1-3, pp. 73-79, 0301-4622

Westrick, J. A., Peters, K. S., Ropp, J. D.\&Sligar, S. G. (1990). Role of the arginine-45 salt bridge in ligand dissociation from sperm whale carboxymyoglobin as probed by photoacoustic calorimetry. Biochemistry, 29, 28, pp. 6741-6746, 0006-2960

Wilson, J., Phillips, K.\&Luisi, B. (1996). The Crystal Structure of Horse Deoxyhaemoglobin Trapped in the High-affinity (R) State. J. Mol. Biol., 264, 4, pp. 743-756, 0022-2836

Yang, F.\&Phillips Jr, G. N. (1996). Crystal Structures of CO-, Deoxy- and Met-myoglobins at Various pH Values. J. Mol. Biol., 256, 4, pp. 762-774, 0022-2836

Ye, X., Demidov, A.\&Champion, P. M. (2002). Measurements of the Photodissociation Quantum Yields of $\mathrm{MbNO}$ and $\mathrm{MbO} 2$ and the Vibrational Relaxation of the SixCoordinate Heme Species. J. Am. Chem. Soc., 124, 20, pp. 5914-5924, 0002-7863 
Yonetani, T., Park, S. I., Tsuneshige, A., Imai, K.\&Kanaori, K. (2002). Global allostery model of hemoglobin. Modulation of $\mathrm{O}(2)$ affinity, cooperativity, and Bohr effect by heterotropic allosteric effectors. J. Biol. Chem., 277, 37, pp. 34508-34520, 0021-9258 


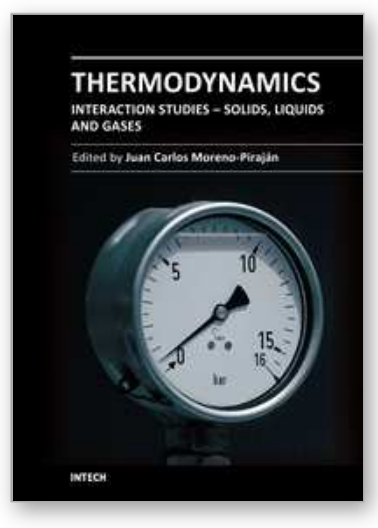

\author{
Thermodynamics - Interaction Studies - Solids, Liquids and Gases \\ Edited by Dr. Juan Carlos Moreno Pirajễin
}

ISBN 978-953-307-563-1

Hard cover, 918 pages

Publisher InTech

Published online 02, November, 2011

Published in print edition November, 2011

Thermodynamics is one of the most exciting branches of physical chemistry which has greatly contributed to the modern science. Being concentrated on a wide range of applications of thermodynamics, this book gathers a series of contributions by the finest scientists in the world, gathered in an orderly manner. It can be used in post-graduate courses for students and as a reference book, as it is written in a language pleasing to the reader. It can also serve as a reference material for researchers to whom the thermodynamics is one of the area of interest.

\title{
How to reference
}

In order to correctly reference this scholarly work, feel free to copy and paste the following:

Jaroslava Miksovska and Luisana Astudillo (2011). Time Resolved Thermodynamics Associated with Diatomic Ligand Dissociation from Globins, Thermodynamics - Interaction Studies - Solids, Liquids and Gases, Dr. Juan Carlos Moreno PirajÃ in (Ed.), ISBN: 978-953-307-563-1, InTech, Available from:

http://www.intechopen.com/books/thermodynamics-interaction-studies-solids-liquids-and-gases/time-resolvedthermodynamics-associated-with-diatomic-ligand-dissociation-from-globins

\section{INTECH}

open science | open minds

\section{InTech Europe}

University Campus STeP Ri

Slavka Krautzeka 83/A

51000 Rijeka, Croatia

Phone: +385 (51) 770447

Fax: +385 (51) 686166

www.intechopen.com

\section{InTech China}

Unit 405, Office Block, Hotel Equatorial Shanghai

No.65, Yan An Road (West), Shanghai, 200040, China 中国上海市延安西路65号上海国际贵都大饭店办公楼 405 单元

Phone: +86-21-62489820

Fax: +86-21-62489821 
(C) 2011 The Author(s). Licensee IntechOpen. This is an open access article distributed under the terms of the Creative Commons Attribution 3.0 License, which permits unrestricted use, distribution, and reproduction in any medium, provided the original work is properly cited. 